at one time, on account of the comparative safety attending its storage and the necessary manipulation of it. Moreover, it has been well established by experiments of many kinds carried out on a considerable scale, as well as by accurate scientific observations, that the detonation of wet gun-cotton is decidedly sharper or more violent than that of the dry material; a circumstance which affords an interesting illustration of the influence exerted by the physical condition of the mass upon the facility ;with which detonation is transmitted from particle to particle. In the determinations made by means of the Nobel chronoscope, of the velocity with which detonation is transmitted along layers or trains of gun-cotton and nitro-glycerine, the lecturer has included experiments with gun-cotton containing different proportions of water. When the material contained 15 per cent. of the liquid, some indications were obtained that the rate of transmission of detonation was a little higher than with dry guncotton; the difference was very decidedly in favour of wet guncotton, when the latter was thoroughly saturated with water. The air in the masses of compressed gun-cotton being replaced entirely by the comparatively incompressible body, water, the particles of explosive are in a much more favourable condition to resist displacement by the force of the detonation, and hence they are more readily susceptible of sudden chemical disintegra. tion. Moreover, the variations in the rate of travel of detonation in dry gun-cotton, resulting from differences in the compact. ness or rigidity of different masses of the material, are very greatly reduced, if not entirely eliminated, by saturating the disks with water, and thus equalising their power of resisting motion by a sudden blow.

Another striking illustration of the influence which the physical character of an explosive substance exercises over its susceptibility to detonation and the degree of facility with which its full explosive force is developed, is furnished by one of the most recently devised, and one of the most interesting of existing, explosive agents.

Twelve years ago, soon after the process of producing com. pressed and granulated gun-cotton had been elaborated by the lecturer, it occurred to him to employ these forms of gun-cotton as vehicles for the application of nitro-glycerine. A considerable proportion of the liquid was absorbed by the porous masses of gun-cotton, and a nitro-glycerine preparation analogous in character to dynamite was thus obtained. The absorbent was in this case a violently explosive body instead of an inert solid as in dynamite, but the quantity of nitro-glycerine in a given weight of the preparation (to which the name of glyoxilin was given), was considerably less than in the kieselguhr-preparation; hence the latter was nearly on a point of equality with it, in regard to power, as an explosive agent.

(To be continued.)

\section{NOTES FROM RUSSIA}

Geography and Anthropology.-At the last meeting, April 23, of the Imperial Russian Geographical Society, M. Sreznefsky, the Secretary, communicated his monthly report on the work of the Society. This consisted in equipping three expeditions in which the Society intends to take part, and its participation in the Anthropological Exbibition of Moscow. The first expedition is the cruise of the steamer Nordenskjold, equipped by the well-known merchant of Siberia M. Sibiriakoff, for the relief of Prof. Nordenskjöld in the Vega. It will proceed from Malmö direct to Yokohama, Behring Strait, and beyond. According to the request of M. Sibiriakoff the Society appointed to accompany the expedition M. A. W. Grigorieff, an accomplished botanist, known for his dredging work in the White Sea, where be collected very interesting specimens of marine fauna with deep soundings and temperature observations, by means of a Negretti and Zambra deep-sea thermometer. He proceeds to Malmö to join the expedition, with a Dent chrono. meter from the Society, and a complete provision for zoological collections, and a sufficient provision of alcohol

The second expedition is sent out by the Ministry of Public Works, for the exploration of the old bed of the Amu-daria (Usboi), and to investigate the possibility of turning the river to the Caspian; it will be under the direction of Major-General A. T. Gloukhofskoi, an experienced traveller in Central Asia. The Society sends two Fellows with the expedition, a geologist, Prince Sedroiz, and the economist, N. A. Majef, the manager of the Turkatan News, a collector of varied statistical materials in Turkestan. The third expedition, of a private character, is to explore for a railroad from Orenburg to Tashkent, and the possibility of navigating with steamers the Sir and Amu-daris. By order of the Emperor a sum of 5,000 roubles is placed at the disposal of the Society.

The Anthropological Exhibition was opened in Moscow on April 15, under the superintendance of the Society, which has sent a great number of valuable objects of an ethnological character, with craniological collections and prehistorical specimens, tumuli excavations, and a valuable collection belonging to the Czarevich. All these collections were arranged by $\mathrm{M}$. Sreznefsky, the Secretary of the Society, who was sent as its representative to the opening of the exhibition. The aim of this exhibition is: (I) To contribute to the development of anthropology as a science. (2) The foundation of an anthropological museum for the teaching of anthropology in the University of Moscow. (3) To popularise the science.

The exhibition is divided into sections-prehistorical, anthro pological, medico-anthropological, photographical, ethnographical, the history of Russian types.

At the end of the meeting of the Society M. Alenitzin communicated his paper on the history of the Amu-daria question ; he criticised the different opinions on the possibility of turning the Amu-daria into the Caspian, and doubted whether this question could be resolved practically and in a positive manner.

\section{A. LomonossofF}

\section{UNIVERSITY AND EDUCATIONAL INTELLIGENCE}

THE Council of the Society of Arts having received an application from the City and Guilds of London Institute for the Advancement of Technical Education, offering to take charge of the technological examinations established by this Society in I873, and carried on to the present time, have resolved to transfer these examinations to the charge of the Institute. The Council have also ascertained that the Science and Art Department will assist the City Institute in conducting the examinations, in the same way as it has hitherto assisted the Society of Arts. The technological examinations for the present year will, therefore, be carried on under the direction of the Institute, and all communications on the subject should be addressed to the Hon. Secretaries, City and Guilds of London Institute, Mercer's Hall, E.C.

The following is the result of the recent examination for the Public Schools Prize Medals of the Royal Geographical Society : Physical Geography (examiner John Ball, F.R.S.), gold medal, Matthew George Grant; silver medal Frank Taylor Sharpe, both of Liverpool College. Honourably mentioned : E. G. Harmer, University College School; H. I.1. Smith, Bristol Grammar School; F. S. Carey, Bristol Grammar School; A. T. MacConkey, Liverpool College. Political Geography (examiner Canon Tristram, F.R.S.), gold medal, David Bowie, Dulwich College. Silver medal, Claude L. Bickwell, Harrow School. Honourably mentioned, J. F. Naylor, Dulwich College; W. H. D. Boyle, Eton; A. D. Rigby, Liverpool College; Theod. Brooks, London International College; R. A. Fawcett and A. C. Painter, of Clifton College.

ON May I an interesting ceremony took place at St. Barbe, the principal free institution at Paris. Two bodies of pupils were marched under the direction of teachers; the first was going to the Gare du Nord in order to come to London and spend six months in a corresponding English institution to learn the English language; the other went to the Gare de l'Est to proceed to Germany. These pupils have already learned foreign languages in Paris. They are placed under the supervision of professors, so that the usual routine of their studies for French. honours should not be interrupted in any way.

\section{SCIENTIFIC SERIALS}

Annalen der Physik und Chemie, No.3-In view of contradictory results got by Sir W. Thomson and M. Le Roux, with regard to the thermo-electric behaviour of stretched wires, Herr Cohn has made a number of experiments, here described in an inaugural dissertation. He finds that the intensity of the thermo. current between stretched and unstretched wire of the same metal, depends (apart from all permanent properties), not only on the present tension of the former, but also, in very different 
degree according to the material used, on the upper and lower limits between which, since the last complete release from tension, the tensions have varied (the succession alone, not the time, being here determinant). In a thermo element of two similar wires, stretched with equal weights, but of which one $(a)$ has last borne a greater, the other $(b)$ a less weight, the current flows from $b$ to $a$. In iron and steel the previous tensions even affect the direction in which the thermo-current varies with increasing or decreasing tension. Taking the direction of the current which arises with the first weak stretching, it is opposite for hard and soft wires, and the discordance above referred to is thus explained. Herr Cohn thus formulates his general conclusion : "A stretched wire behaves, ceteris paribus, differently, according as it has before been stretched more weakly or more strongly, and this difference continues till the next alteration of the tension." - Herr R. Weber contributes a useful paper on the chemical composition of glasses with relation to their resistance to atmospheric influences. He finds that the composition of many well tested lime alkali glasses approximates the proportions $6 \mathrm{SiO}_{2}$, $\mathrm{ICaO}$, and $\mathrm{rK}_{2} \mathrm{O}$ or $\mathrm{Na}_{2} \mathrm{O}$; but also, in good glasses, there may be more alkali, if it be compensated with more than 6 equivalents of silicic acid; and less silicic acid may be allowed if the lime be diminished relatively to the alkali.-The transmission of high tones through the telephone is discussed by Herr Hagenbach. From his experiments it appears that the (upper) limit of audibility with the instrument is commonly about two octaves lower than in direct hearing. The cause is found not in the line, nor in the magnet, but in the plate, which, when the variations of magnetism exceed a certain number per second, no longer keeps up with them. - Herr Aron gives a mathematical study of the microphone ; inter alia, it is shown that, whereas in the telephone the "clang tint" is exalted, in the microphone it is lowered.-Herr Herwig prosecutes his study of liquid cells as condensers ; considering the charge of cells, first by large constant batteries, then by small forces (both acting shortly), and comparing the full charges in cells containing liquids of different resistances.-We further note a new hygrometer by Herr Edelmann, based on the fact that if any space be filled with atmospheric air, and the aqueous vapour then removed, without altering the volume, the pressure decreases by the amount of tension of this vapour. A sinus manometer for measuring small differences of air-pressure (Thomsen), and a simple regulator for the electric light (Stöhrer) are also described.-Ferr Fröhlich shows the bearing of the principle of conservation of energy on the theory of diffraction.

THe Rivista Scientifico-Industriale, (1879, No. 7) contains the following papers of interest :-On some prehistoric discoveries in Sicily, by Prof. Francesco Mangini.-On the lengthening of filiform conductors traversed by an electric current, by Prof. G. Basso.-On the optic rotatory power of quartz and its variation with temperature, by $\mathrm{M}$. Joubert.-On digallic acid, by Prof. U. Schiff.-On some phenomena due to the viscosity of liquids, by Prof. Carlo Marangoni.--On Sargasso seas, by the same.On Helmholtz' double siren, by the editor.

\section{SOCIETIES AND ACADEMIES LONDON}

Royal Society, February 20 and 27, and April 3.- "On the Reversal of the Lines of Metallic Vapours," Nos. iv., v., and vi., by Professors Liveing and Dewar.

In the first of these experiments the metals were produced by chemical reactions within the tubes, used as before described. They found that cæsium chloride alone heated in glass tubes gave no absorption lines, but crsium and rubidium chlorides when heated with metallic lithium each showed its characteristic absorption lines. Charred tartrate of cæsium heated in a furnace in a narrow porcelain tube gave very readily the two lines in the blue reversed, and charred rubidium tartrate the two violet lines reversed, but no reversal in any other part of the spectrum. When charred potassium tartrate was treated in the same way, a broad absorption band was seen extending from wave-length about 5,700 to about 5,775 . This band was also seen for a short time bright, when the material was put into the tube before it was heated, and the light observed as the tube got hot. It was also seen bright in the induction-spark taken between platinum and potassium in carbonic oxide. Besides this band the vapours from the charred potassium tartrate produced another absorption band in the red, and two more in the blue. None of these absorp- tions "correspond with those seen when potassium is heated in hydrogen, or with known emission lines of that metal, though the first and most conspicuous is near a well-known group of three bright lines of potassium. Charred sugar mixed with carbonate of soda gave only the same absorption as sodium in hydrogen. A mixture of barium carbonate, lamp.black, and aluminium filings gave dark bands corresponding to the bright bands seen when sparks are taken from a solution of barium chloride marked $\alpha, \beta$, and $\delta$ respectively by Boisbaudran; and at the highest temperature of the furnace fed with Welsh coal a mixture of charred barium tartrate and aluminium gave the barium line wave-length 5535 sharply reversed. Charred strontium and calcium tartrates with aluminium gave no reversals, but with the addition of sodium or potassium carbonate the wellknown blue line of strontium and violet line of calcium were reversed. The temperature at which these results were obtained was reached by the use of gas retort carbon as fuel, and was such that iron tubes well coated with fire-clay gave way in a few minutes.

The next experiments were made with tubes bored out of lime and heated at the bottom by a jet of coal-gas and oxygen intro. duced through a lateral opening. In these, as in the previous experiments, the hot bottom of the tube itself (not an independent light as used by Messrs. Lockyer and Roberts in their experiments with lime tubes) gave the luminous background. In this way the violet line of calcium was reversed, the red line of lithium and the orange and green bands of lime appeared with dark lines down their middles.

A larger series of experiments was made with similar tubes of lime, but with an electric arc introduced through lateral openings as the source of light and heat. In some cases a tube bored in a block of gas carbon was employed, and was then made one of the electrodes. The carbon tubes, however, were found to conduct away the heat, and though they lasted much longer, did not in general succeed so well as the lime tubes. In same cases aluminium was used as a reducing agent, and in others more volatile substances, viz., potassium and sodium carbonates, were used to increase the amount of vapour carried up into the tube; and in others a current of hydrogen was introduced.

Of the calcium lines the violet line (4226) was almost always seen expanded with a dark middle, and the three brightest lines in the indigo were often in a similar condition. The addition of aluminium generally made them appear as dark bands on a continuous background. Of the two Fraunhofer lines $\mathrm{H}$, the more refrangible $(\mathrm{K})$ was the first to appear reversed, and remained so the longer. Other calcium lines reversed were, one in the green $(5188)$, and, much less easily, two in the red $(6161,6121)$, one more in the indigo (4302), and one in the blue (4877).

In the case of strontium, the well-known blue line was easily reversed, and two lines in the violet $(4215,4077)$, less easily five lines in the blue $(48 \mathrm{I} 2,483 \mathrm{I}, 4868,4873,4895)$, and, by the aid of aluminium, one in the green (4962). In the case of barium, besides the persistent ray 5535, two other lines in the green $(5518,4933)$, a line in the blue $(4553)$, and one in the orange (6496), were reversed.

With magnesium the $b$ group were expanded and reversed in an order the inverse of their refrangibility. The other lines of that metal were expanded, but not reversed, and the blue line, $448 \mathrm{I}$, conspicuous in the spark between magnesium electrodes, was not seen at all. This line does not appear in Capron's pho tographs of magnesium in arc. An attempt to re-introduce it by combining the action of an induction spark with that of the are in a lime tube failed owing to the conducting power of the hot gases and walls of the tube, and will probably only succeed with a pressure of several atmospheres in the apparatus. The simila: disappearance of the cadmirm lines 5377 and 5336 was als noticed.

In using potassium carbonate the two extreme pairs of ines, in the violet and red respectively, were readily reversed; les readily the three lines in the greenish-yellow, other two lines in the red $(6913,6946)$, a group of three in the orange $(5353,5338$, 5322 ), and the least refrangible (5112) of another triplet in the green.

Using sodium chloride, the pair of lines next more refrangibic than $D$ were repeatedly reversed, the less refrangible being the first and most strongly reversed, as has also been observed by Mr. Lockyer. A second pair of bright lines usually came out at the same time, like ghosts of the first, on the more refrangible side.

With lithium chloricie, the red and blue lines were easily re. 